$176 \mathrm{pp}$., but also 121 illustrations-it is gratifying to have it available in English in so well produced a form.

IVOR MONTAGU

Tigers, by Guy Mountfort. David \& Charles, £2.25.

I wonder what William Blake, when some 100 years back, he wrote those oft-quoted words, would have thought of the present-day tiger situation. More than 60 years ago the reviewer, serving in the Indian Army at a time when tigers abounded, was familiar with 'stripes' in the open woodland haunts in the Central Provinces where a system of strictly controlled shooting blocks was administered by the Forest Department: during one memorable morning twelve came to drink at a river-bed pool. Paradoxically, this was the most effective conservation method one could wish: the tiger population in each block was well known and never permitted to fall below a limit which would inhibit satisfactory recuperation. Villagers were allowed to destroy cattle marauders, though this rarely happened, as an abundance of deer, antelopes and wild swine provided ample tiger food. But the 1914-1918 war heralded an era of change.

Guy Mountfort deals comprehensively with every aspect of a tiger's life, with the maneater problem, distribution in the past, present status, and the operative measures to save so noble a creature. A most useful summary of information includes a map of the existing tiger reserves.

The book is profusely illustrated in colour but some criticism is justifiable, for whereas a superb picture of a tiger in all its feline glory appears on the glossy dust cover, the reproduction of a series of photos of varying merit on the semi-art paper of the text leaves much to be desired. Reproduction on a glossier surface of some of the better pictures would have enhanced the value of so praiseworthy an undertaking.

C. R. S. PITMAN

Tiger Haven, by Arjan Singh. Macmillan, £2.95.

It was providential that three books concerning the tiger should be published during the year when the World Wildlife Fund was concentrating its international efforts on saving the species from probable extinction. Arjan Singh, a dedicated tiger-watcher and conservationist, has made an important contribution to public awareness of the threat by this book, which in no way duplicates the other two.* It is a personal account of his one-man crusade to prevent the disappearance of the tiger and other wildlife from one of the few unspoiled areas on the border between northern Uttar Pradesh and Nepal. He writes with enthusiasm, and he is outspoken in his criticism of the bureaucratic obstructions he had to overcome in winning official recognition for the sanctuary he has created at Dudwa. Conservation needs men of this calibre, who are not afraid to keep on reminding us that the survival of endangered species such as the tiger cannot be achieved at the agonisingly slow pace of normal official procedures. He writes also with intimate knowledge of India's wildlife, and his book is the more readable for its pungent comments on commercially sponsored poaching and on the indifference of local officials towards his enterprise.

Arjan Singh is one of India's relatively few wildlife photographers and cinematographers; some of the numerous illustrations in his book lack clarity, but most of them were taken under the difficult conditions of dense forest, where the major animals can be observed only at dawn or dusk. In a

* The other two are Guy Mountfort's own book Tigers, reviewed above, and Wild Beauty, by Kailash Sankhala - see page 495 . 


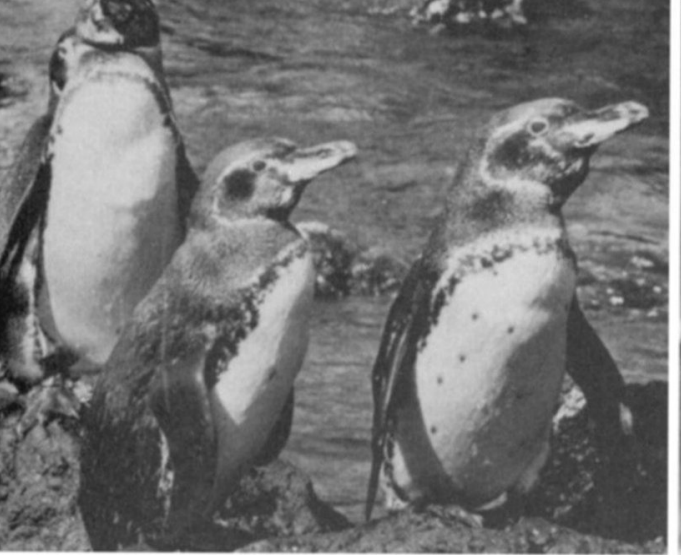

Galapagos penguins, the tool-using cactus finch and the land iguana, three endemic Galapagos species photographed by Roger Perry, formerly Director of the Charies Darwin Research Station, and author of The Galapagos /s/ands

country where the increasing pressure of human numbers imposes the utmost difficulty on setting aside even the smallest tract of land for wildlife, a reserve such as Tiger Haven, small though it is, can be invaluable. Arjan Singh's sanctuary contains not only tigers and leopards, but also the largest surviving population of barasingha deer in India-about 1200 animals. Throughout Asia, only the Sukia Phanta reserve in western Nepal can today match this total. For this reason alone it is to be hoped that his book will help to gain for his initiative the recognition it deserves.

GUY MOUNTFORT

\section{Conservation for Survival, by Kai Curry-Lindahl. Gollancz,} £3.25.

The author has assembled an enormous number of ecological facts to support his central theme that, 'since we ourselves are biological organisms dependent on the natural environment', we must end our senseless destruction of the life support systems of nature. The impact of our activities on the air, the sea, fresh water, soil, vegetation, animals, and ultimately on ourselves makes it clear that the warnings of environmentalists over the past few years have not been fanciful. The pollution caused by carbon monoxide from automobiles is by now well documented, but it is disturbing to find that the take-off of a single Boeing 707 has the same pollution effect as 6850 accelerating Volkswagens.

Pollution of the environment upsets the working of nature in quite unpredictable ways, and herein lies its greatest danger. The destruction by the crown of thorns starfish Acanthaster planci of coral islands in the Pacific has aroused worldwide concern. The productivity of these coral reefs is responsible for several food chains in the oceans. It has been suggested that dredging and blasting of areas around the coral reefs has killed off the predators which prevented a population explosion of these starfish. The author feels that the discovery of these starfish in polluted areas near Port Sudan may be a pointer to the connection between pollution and the unchecked increase of the starfish.

Kai Curry-Lindahl has always insisted that wild animals are much better adapted to thrive on marginal lands than cattle. Millions of years of evolution has ensured that wild species fit perfectly into ecological niches where they live. Many antelopes for example, require hardly any water; they start to breed when they are less than a year old, which, coupled with a short gestation period, makes them extremely productive; their metabolism is such that they convert vegetation into meat most effectively. The problem, 